\title{
DESOXYCORTICOSTERONE ACETATE AND OESTRADIOL DIPROPIONATE THERAPY IN THE NEWBORN INFANT
}

BY

\author{
R. A. MILLER, M.D.* \\ (From the Royal Infirmary, Edinburgh)
}

This paper is devoted to the study of oestrogenic and adreno-cortical action upon the gastric acidity and weight progress of the infant during the first ten days of life. It is known that the influence of the hormone oestrin upon the growth of the premature infant, more particularly in girl babies, is stimulating (Moncrieff, 1936; Potter, 1937). Its action upon the gastric acidity, however, has only been observed in adults, in whom no difference could be detected by Atkinson (1939) or Sandweiss et al. (1939). The influence of desoxycorticosterone acetate in infancy has not been recorded, and Bruch and McCune (1936) did not consider such therapy was indicated. Nevertheless, a degree of adrenal insufficiency may be present as there is a haemoconcentration, and a raised non-protein nitrogen and serum protein during the first days of life, as well as involution of the suprarenal gland.

\section{Investigation}

The behaviour, weight, progress, and gastric secretion of sixty babies has been studied during the first ten days of life. The infants were divided into three groups of twenty, with an equal number of girl and boy babies in each. The purpose of having groups was to keep one as a control, while the others were treated with either oestradiol dipropionate (Ovocyclin-P) or desoxycorticosterone acetate (Percorten). The oestradiol compound was chosen because its potency is far greater than that of oestrin, theelin, emmenin, trihydroxyoestrin or ketohydroxyoestrin which have been used for similar investigations. The dose was $1 \mathrm{mgm}$. intramuscularly on the first day of life, and it was repeated on the fourth day in ten of the cases. Percorten was also given intramuscularly, but on the first, fourth and eighth days of life, the dose being 5 mgm. on each occasion.

The gastric acidity was investigated on the second, fifth and seventh days of life after the infants had been starved for seven to eight hours. The fasting

* Working under the auspices of the Kirk Duncanson Fellowship for Medical Research, The Royal College of Physicians, Edinburgh. 
juice was first withdrawn and then a test-meal was given. It consisted of equal parts of breast-milk and water and amounted to one drachm per pound body weight. After the meal three specimens of gastric contents were taken at halfhourly intervals, except in the group of infants treated with desoxycorticosterone, in whom the last specimen was omitted. When possible, 1 c.c. of each sample was quantitatively analysed for free and total acidity by titrating it with $\mathrm{N} / 70 \mathrm{NaOH}$ from a microburette. The end point of the titration was determined with Topfer's reagent and phenolphthalein as indicators.

The results of the total acidity are expressed in c.c. $\mathrm{N} / 10 \mathrm{HCl}$ per 100 c.c. gastric contents, and recorded in fig. 1 . The only significant difference between

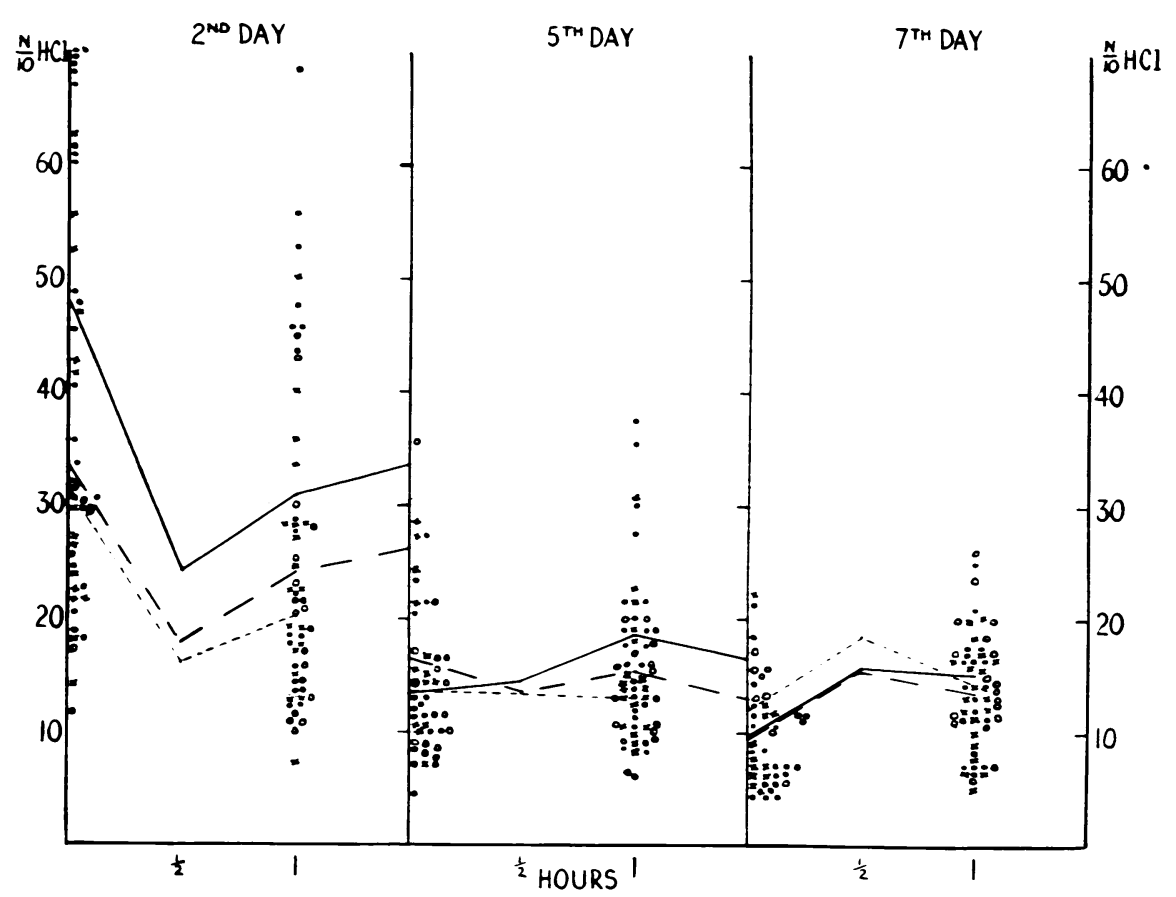

FIG. 1.-To show the total acidity

Continuous line represents average for control group.

Coarse interrupted line average for oestradiol group.

Fine interrupted line average for Percorten group.

Dots indicate individual readings in control group.

Crosses indicate individual readings in oestradiol group.

Circles indicate individual readings in Percorten group.

the curves for total acidity in the three groups is the higher acidity for the control group on the second day of life. This is probably a coincidence arising from the great variation in the total acidity during the first two days of life. It is not evidence that the hormones lower the acidity, as the difference does not persist throughout the first week of life. The average values for free acidity are given in table 1 , where they are expressed in c.c. $\mathrm{N} / 10 \mathrm{HCl}$ per 100 c.c. gastric contents. The brief account suffices, for the free acid was only 
present on the second day of life. This is not surprising, as the free acid does not usually appear unless the total acidity exceeds 30 c.c. $\mathrm{N} / 10 \mathrm{HCl}$, and this only occurred three times on the fifth day and once on the seventh day of life.

TABLE 1

\begin{tabular}{|c|c|c|c|c|c|c|}
\hline \multicolumn{3}{|c|}{ GROUP } & \multirow{2}{*}{$\begin{array}{c}\text { FASTING JUICE } \\
18 \cdot 3\end{array}$} & \multirow{2}{*}{$\frac{\frac{1}{2} \text { HR. P.C. }}{0 \cdot 2}$} & \multirow{2}{*}{$\frac{1 \text { HR. P.C. }}{2.5}$} & \multirow{2}{*}{$\frac{1 \frac{1}{2} \text { HR. P.C }}{3 \cdot 7}$} \\
\hline Control & . & . & & & & \\
\hline Oestradiol. & . & . & $8 \cdot 8$ & 0.6 & 0.8 & $5-0$ \\
\hline Percorten & . & . & $5 \cdot 1$ & 0.7 & $1 \cdot 5$ & - \\
\hline
\end{tabular}

The influence of the hormones upon the total acidity of the two sexes is demonstrated in fig. 2. In it an equal number of male and female infants

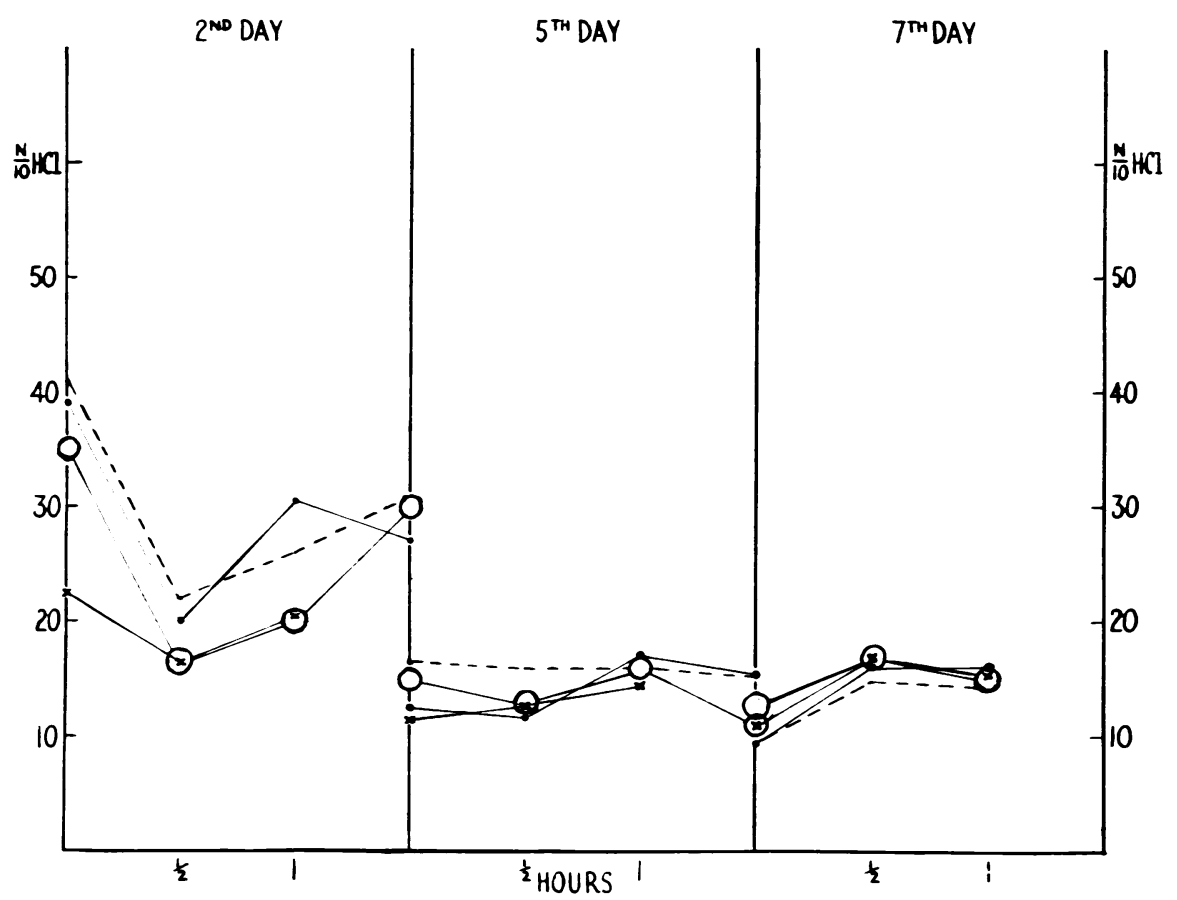

FIG. 2.-Comparison of total acidity in both sexes

Dot represents female control group.

Circle represents female oestradiol group.

Cross represents female Percorten group.

Interrupted line represents all male infants.

are compared in each group. The gastric acidity does not vary with sex or with hormone therapy during the first week of life; it does not therefore behave as in older infants, since the male is supposed to have a more acid secretion than the female (Tomotake, 1930). 
The effect of hormone therapy upon weight progress. The progress of all the infants was carefully watched and test-feeds given periodically, so that underfed babies might have any deficiency remedied. Their weight progress was not retarded by ill health, although one infant was jaundiced and two suffered from upper respiratory infections, from which no systemic disturbance was noted. The percentage loss of birth weight of the three groups during the first ten days of life is contrasted in fig. 3. The average birth weight of

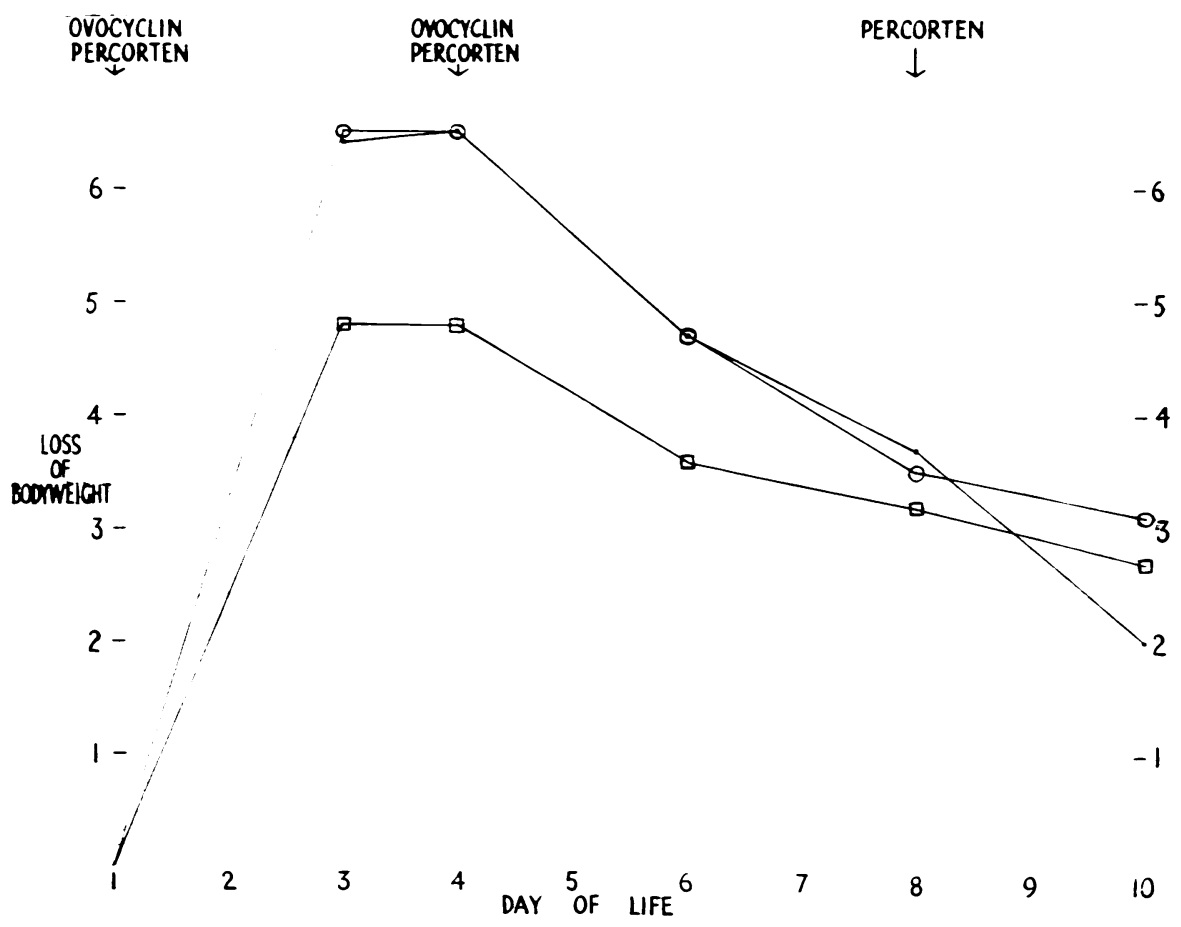

FiG. 3.-Percentage loss of birth weight

Dot, average for control group.

Circle, average for oestradiol group.

Square, average for Percorten group.

the control group of infants was seven pounds, for the one treated with oestradiol it was seven pounds three-and-a-half ounces, and for the one treated with desoxycorticosterone it was seven pounds ten ounces. From the results two facts are plain : first, the progress of the infants treated with the oestrogen is identical with that of the controls. Secondly, infants treated with Percorten show a maximum loss of weight amounting to 4.8 per cent. of their birth weight on the third day of life as compared with 6.5 per cent. in the other infants investigated. Such a difference is significant for Halpern (1934) could not reduce the loss of weight more than 1.14 per cent. This diminution was effected by the administration of an isotonic solution and adequate milk feeds to maintain the infant's weight from the day of birth.

Moncrieff (1936) emphasizes that the girl babies react better to oestrogens 
than the boys. This is supported by table 2 , in which the weight progress of both sexes treated with oestradiol is contrasted. This is probably due to the stimulating action of the endocrine upon the growth of the endometrium in the female. In an attempt to predict the weight progress from the degree of gastric acidity the weight chart of each infant was correlated with its gastric secretory response to test-meals throughout the first week of life. By this means it was impossible to forecast the amount of weight an infant would lose during the week, or the rate at which it would regain its birth weight. However, one interesting fact was noted on the seventh day : only eight infants belonging to either the control or oestrogen group had a total acidity of 20 c.c. or more, and they, on the average, had regained their birth weight on the seventh day of life. Infants treated with Percorten behaved in a similar manner. Eleven of this group had an acidity corresponding in degree to the former groups, and their weight was 1.9 per cent. less than their birth weight of the seventh day as compared with 4.4 per cent. for the remaining infants in the same group.

TABLE 2

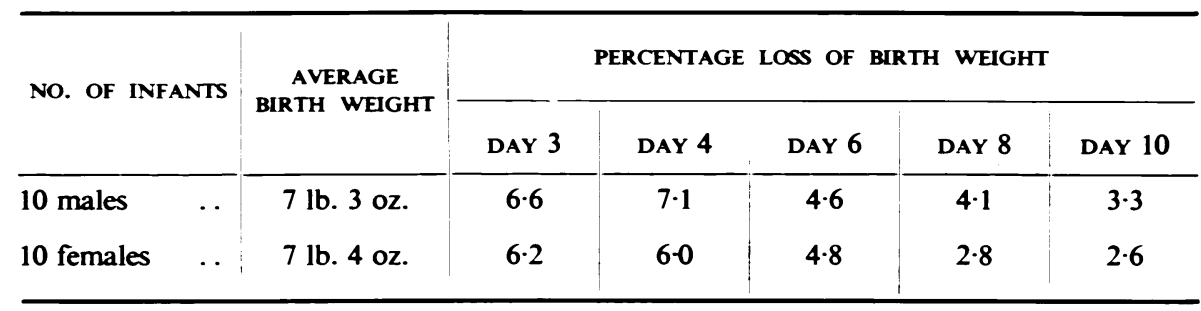

In concluding an account of the results it should be noted that all weights were recorded, but forty-seven of the gastric specimens were either unobtainable or contaminated with bile or blood.

\section{Discussion}

Two problems arise: first, why does the type of secretory response to a test-meal vary so markedly during the first week of life? And, secondly, has the reduction in the physiological loss of weight by means of Percorten any significance? In seeking the explanation of the former, it is necessary to recall the following factors which influence gastric secretion :

(1) Admixture of test-meal with the stomach contents, a factor which is constant throughout the investigation. The swallowing of saliva or regurgitation of intestinal contents may produce changes in the acidity of fasting juice.

(2) Variation in the parietal cell secretion itself, a factor considered of little importance at the present day.

(3) Peptic secretion ; this can be dismissed, as it plays such a minor part.

(4) Reabsorption of hydrochloric acid, which is considered by some authorities to be of importance.

(5) A specific diluting secretion or mucus may also be an important factor. 
Buffer containing fluids, such as protein, phosphates and bicarbonates, will diminish acidity, and they are thought to be primarily responsible for observed variations in the gastric acidity in adults (Hollander, 1939).

Of all these factors, the only one likely to be responsible for the gross alterations in the gastric acidity during the first two or three days of life would be a defect in the mechanism of reabsorption of hydrochloric acid. If this is not accepted, another possible explanation is the presence of a gastrogenic substance in the infant's circulation, received in utero from the mother. At birth its concentration in the blood is similar to that in an adult or in the mother, but, as time passes the concentration falls, with a corresponding diminution in the gastric acidity (Miller, 1941).

Attention has been drawn to the maximum physiological loss of weight at birth. Normally it averages 6.5 per cent. of body weight (Hess, 1922) or 7.5 to 7.8 per cent. (Pfaundler, 1916; Pies, 1911) which is comparable with the figure of 6.4 to 6.5 per cent. for the control and oestradiol groups of infants under investigation. Babies treated with desoxycorticosterone show a striking difference in losing 4.5 per cent. of their birth weight. In the past, the weight loss was considered to result from a combination of factors : passage of $2 \frac{1}{2}$ to $6 \frac{1}{2}$ oz. meconium (Camerer, 1900 ; Hirsch, 1910); depletion of fluid via the skin, lungs, kidneys, and occasionally from the stomach; reduction of body tissue, as evidenced by wrinkling and lack of turgor of the skin; and, lastly, inadequate nourishment. Now, adreno-cortical insufficiency may be added to the above list. The blood biochemistry of the newborn supports the practical demonstration of the hormonic efficiency. In table 3 the rise in the protein and non-protein nitrogen during the first four days of life is apparent. Haemoconcentration beginning at birth is also associated with suprarenal insufficiency. The maximum concentration of the blood occurs six to seventy-two hours after birth as judged by the haematocrit (Bruch and McCune, 1936) and the erythrocyte count (Lippman, 1924). It is suggested that the cause of the above findings results from the involution of the gland or from traumatic shock at birth.

TABLE 3

\begin{tabular}{|c|c|c|c|c|}
\hline \multirow{2}{*}{ DAY OF LFE } & \multicolumn{2}{|c|}{ PROTEIN (GM. PER CENT.) } & \multicolumn{2}{|c|}{$\begin{array}{l}\text { NON-PROTEIN NITROGEN } \\
\text { (MGM. PER CENT.) }\end{array}$} \\
\hline & MARPLES (1932) & BRUCH (1936) & LUCAS (1921) & BRUCH (1936) \\
\hline $\begin{array}{l}1 \\
2 \\
3 \\
4\end{array}$ & $\begin{array}{l}5 \cdot 9 \\
6 \cdot 07 \\
6 \cdot 23 \\
7 \cdot 07\end{array}$ & $\begin{array}{l}6 \cdot 61 \\
6 \cdot 26 \\
6 \cdot 78 \\
7 \cdot 32\end{array}$ & $\begin{array}{l}42 \cdot 2 \\
46 \cdot 3 \\
36 \cdot 3 \\
-\end{array}$ & $\begin{array}{c}35.0 \\
40.6 \\
32.0 \\
-\end{array}$ \\
\hline
\end{tabular}




\section{Conclusion}

There were no toxic reactions or vaginal bleeding produced by oestradioldipropionate or desoxycorticosterone acetate therapy. Nevertheless, massive doses as used in these investigations over a prolonged period may be dangerous. Robson (1940) states that oestrogenic substances can become carcinogenic in their action, and toxic effects upon the kidney have been observed by Korenchevsky (1940). The adreno-cortical hormone, on the other hand, can produce varying grades of oedema which, if not relieved, may terminate in congestive heart failure (Ferrebee et al., 1939).

The weight progress of the female infants may be aided by oestradiol and the maximum physiological loss of weight at birth diminished by desoxycorticosterone; neither of these facts, however, is sufficient to warrant the use of the hormones in normal babies, since the improved weight progress of girl babies is merely the result of a localized hormonic action upon the endometrium of the uterus, and the diminution in the initial loss of weight does not aid the ultimate weight progress.

The gastric acidity was not influenced by the hormone therapy. This is not altogether surprising, for both Atkinson (1939) and Sandweiss (1939) detected no difference in the acidity of stomach contents in man or dogs when they were treated with oestrin. The mother, however, is responsible for the gross variation in her infant's gastric acidity during the first few days of life. The infant's progress in weight is not influenced by the degree of acidity, but it was noted that infants thriving best at a week old had a gastric acidity of 20 c.c. $\mathrm{N} / 10 \mathrm{HCl}$ or more after a test-meal consisting of equal parts of milk and water.

The investigations were performed in the Simpson Maternity Pavilion, The Royal Infirmary, Edinburgh, by kind permission of Prof. R. W. Johnstone, Dr. W. F. T. Haultain, and Dr. Douglas Miller, who allowed the work to be carried out in their wards. The hormones were supplied by Ciba, Ltd., in the form of Ovocyclin-P and Percorten, for which I am grateful. Thanks are especially due to Prof. Charles MacNeil for his guidance and interest, and to Sister Taylor and nursing staff for their co-operation in collecting specimens and observations.

\section{REFERENCES}

Atkinson, A. J., and Ivy, A. C. (1939). Amer. J. Digest. Dis., 5, 30.

Bruch, H., and McCune, D. J. (1936). Amer. J. Dis. Child, 52, 863.

Camerer, W. (1900). Z. Biol., 39, 37.

Ferrebee, J. W., et al. (1939). J. Amer. med. Ass., 113, 1729.

Hess, J. H. (1922). Premature and Congenitally Diseased Infants, Phila., 8-60.

Hirsch, J. (1910). Berl. klin. Wschr., 47, 11-13.

Halpern, L. J. (1934). J. Pediat., 5, 40.

Hollander, F. (1939). Amer. J. Digest. Dis., 5, 364.

Korenchevsky, V., and Ross, M. A. (1940). Brit. med. J., 1, 645.

Lippman, H. S. (1924). Amer. J. Dis. Child., 27, 273.

Lucas, W. P., et al. (1921). Ibid., 22, 524.

Marples, E., et al. (1932). Ibid., 44, 31. 
Miller, R. A. (1941). Arch. Dis. Childh., 16, 22.

Moncrieff, A. (1936). Ibid., 11, 9.

Moore, C. R., and Price, D. (1932). Amer. J. Anat., 50, 13.

Pfaundler, M. (1916). Z. Kinderheilk., 14, 1.

Pies, W. (1911). Mschr. Kinderheilk., 9, 51.

Potter, M. F. (1937). Brit. med. J., 1, 1201.

Robson, R. (1940). Recent Advances in Sex and Reproductive Physiology, London, 66, 72, 303.

Sandweiss, D. J., Saltzstein, H. C., and Farbman, A. (1939). Amer. J. Digest. Dis., 5, 24.

Tomotake, I. (1930). Jhrb. Kinderheilk., 129, 319. 